\title{
Animal Models of Middle Ear Cholesteatoma
}

\author{
Tomomi Yamamoto-Fukuda, ${ }^{1}$ Haruo Takahashi, ${ }^{1}$ and Takehiko Koji ${ }^{2}$ \\ ${ }^{1}$ Departments of Otolaryngology-Head and Neck Surgery and Translational Medical Science, \\ Nagasaki University Graduate School of Biomedical Sciences, 1-7-1 Sakamoto, Nagasaki 852-8501, Japan \\ ${ }^{2}$ Department of Histology and Cell Biology, Nagasaki University Graduate School of Biomedical Sciences, \\ 1-12-4 Sakamoto, Nagasaki 852-8523, Japan
}

Correspondence should be addressed to Tomomi Yamamoto-Fukuda, tomomiyf@nagasaki-u.ac.jp

Received 22 September 2010; Revised 15 December 2010; Accepted 10 February 2011

Academic Editor: Monica Fedele

Copyright (C) 2011 Tomomi Yamamoto-Fukuda et al. This is an open access article distributed under the Creative Commons Attribution License, which permits unrestricted use, distribution, and reproduction in any medium, provided the original work is properly cited.

\begin{abstract}
Middle ear acquired cholesteatoma is a pathological condition associated with otitis media, which may be associated with temporal bone resorption, otorrhea and hearing loss, and occasionally various other complications. Cholesteatoma is characterized by the enhanced proliferation of epithelial cells with aberrant morphologic characteristics. Unfortunately, our understanding of the mechanism underlying its pathogenesis is limited. To investigate its pathogenesis, different animal models have been used. This paper provides a brief overview of the current status of research in the field of pathogenesis of middle ear acquired cholesteatoma, four types of animal models previously reported on, up-to-date cholesteatoma research using these animal models, our current studies of the local hybrid ear model, and the future prospect of new animal models of middle ear cholesteatoma.
\end{abstract}

\section{Introduction}

Middle ear acquired cholesteatoma is a pathological condition associated with otitis media $[1,2]$, and as the cause of otorrhea, hearing loss, and occasionally complications such as facial palsy [3], brain abscess, and meningitis [4]. Recurrence after surgical treatment is very common [5]. Middle ear acquired cholesteatoma is morphologically characterized by epithelial cell proliferation and granulation tissue formation. Unfortunately, despite many studies our understanding of the mechanisms underlying the pathogenesis of cholesteatoma is limited. Four predominant theories of the genesis of cholesteatoma formation have been proposed.

(1) Metaplasia Theory. in 1873, Wendt [6] suggested that metaplasia of the mucosa of the middle ear into the keratinizing epithelium led to cholesteatoma. Sadé et al. [7, 8] proposed that chronic irritation can cause the mucosal lining of the middle ear to convert to a keratinizing epithelium.

(2) Immigration Theory. Bezold in 1890 [9] and Habermann

[10] described immigration theory. Friedmann [11] and
Tumarkin [12] have been more contemporary supporters of this aspect, which proposed that squamous epithelium migrates through a defect in the tympanic membrane in an effort to cover areas of inflammation in the middle ear.

(3) Hyperplasia Theory. Rüedi [13] presented evidence that supported the basal cell hyperplasia (papillary proliferation) theory first published by Manasse et al. [14] in 1917. As the result of inflammation of the middle ear, the proliferation of epithelial cones in the basal layers of the keratinizing epithelium of Shrapnell's membrane leads to cholesteatoma formation.

(4) Retraction Pocket Theory. Bezold in 1890 [9] first described this currently most-accepted theory that proposes that acquired cholesteatoma develops from retraction pockets [15]. A retraction of Shrapnell's membrane as a result of chronic dysfunction of the Eustachian tube might progress into cholesteatoma formation.

4(a) Habitual sniffing theory was described as under the heading of retraction theory. Habitual sniffing 
associated with closing failure of the Eustachian tube is believed to be closely related to the etiology of retraction-type cholesteatoma [16-18]. It seems that such sniffing induces a high negative pressure in the middle ear and may sometimes promote the development of cholesteatoma or its recurrence after surgery $[19,20]$.

Currently, the retraction pocket theory has many supporters following clinical observation, and there is clinical evidence for the "retraction and proliferation theory" on the pathogenesis of cholesteatoma [21, 22]. Sudhoff and Tos [23] suggested the proliferation of epithelial cells in the retraction pocket was altered by inflammatory stimuli of the subepithelial connective tissue and that this excessive proliferation may finally lead to cholesteatoma formation. They proposed a four-step concept for the pathogenesis of cholesteatoma that combined the retraction and proliferation theories: (a) the retraction pocket stage, (b) the proliferation stage of the retraction pocket, subdivided into cone formation and cone fusion, (c) the expansion stage of attic cholesteatoma, and (d) bone resorption (Figure 1, [24]). But, there was a lack of explanation for the transition from a retraction pocket to cholesteatoma.

Animal models are very important for studying the pathogenesis of acquired cholesteatoma [25-27]. Chinchillas, guinea pigs, Mongolian gerbils, Meriones unguiculatus, and rats have been used to make animal models of cholesteatoma. In several studies, chinchillas were used because their auditory apparatus is similar to that of humans [28]. On the other hand, pigs were used for temporal bone pneumatization models because they have a mastoid (Figure 2) [29]. The gerbil is the only nonhuman animal known to spontaneously develop aural cholesteatomas [25, 30]. The ultrastructure of the epithelial and subepithelial linings of the gerbilline middle ear are similar to that of the human [31], and destructive characteristics of the gerbilline cholesteatoma closely mimic human cholesteatoma [32]. Chole et al. [25] indicated that aural cholesteatoma were found to arise spontaneously in $45.7 \%$ of gerbilline ears studied. Henry et al. [30] indicated that both the prevalence of spontaneous cholesteatoma and the resultant peripheral auditory evoked potential threshold increased from 6 to 18 months of age. Chole et al. [25] and Henry et al. [30] described five stages of spontaneous gerbilline cholesteatomas (Figure 3, [30]). Stage I is an accumulation of keratin debris on the outside surface of the tympanic membrane; stage II has a medial displacement of the tympanic membrane into middle ear without contact with the middle wall of the bulla; stage III, the cholesteatoma is in contact with the prominence of the cochlea; in stage IV, cholesteatoma fills the bulla; in stage V, the cholesteatoma extends intracranially. The stage of development of the cholesteatoma varied as a function of age. Most of the affected 6- and 12-month-old gerbils (younger gerbils) had stage I or II cholesteatomas. More than half of the 18- and 24-month-old gerbils (older gerbils) had stage III or stage IV cholesteatomas. Some of the oldest gerbils were at stage V, with the cranial cavity being invaded. Also, in 2006, Tinling

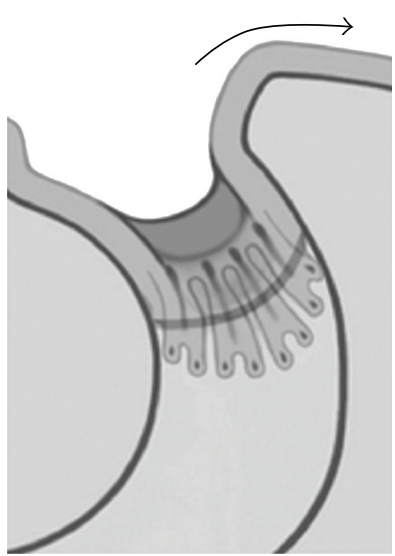

(a)

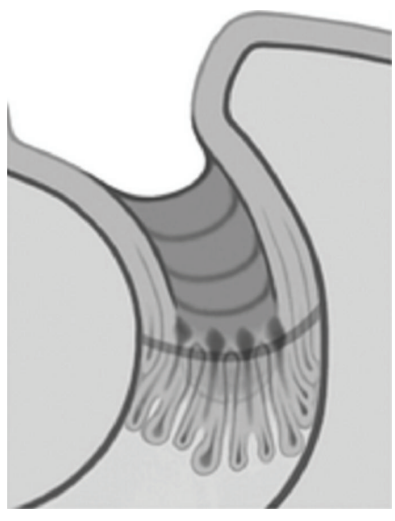

(c)

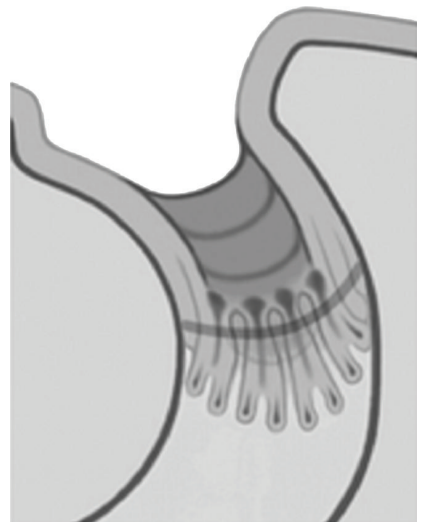

(b)

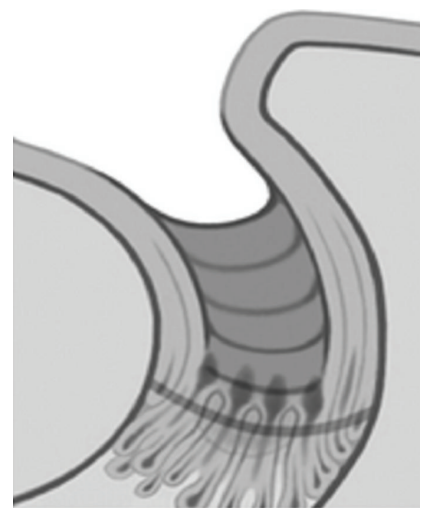

(d)
FIGURE 1: Schematic illustration of the expansion stage written by Sudhoff and Tos [24]. (a) Expansion of sinus cholesteatoma, and the lakes of keratin are opened to the surface of the retraction wall in the depth the cones are proliferating and growing. Lateral migration and cell cleaning is superficially still possible (arrow) (reproduced with modification with permission from [24]). (b) The cholesteatoma has expanded by the length of the cone. In the depth, new microcholesteatoma are formed within the new cones (reproduced with modification with permission from [24]). (c) The keratin lakes are fused, moving the border of the matrix further towards the attic (reproduced with modification with permission from [24]). (d) Further expansion of attic cholesteatoma. Establishment of a vicious circle in the following ways: proliferation at the bottom of the cone, keratin formation within the cones, fusions of microcholesteatomas, and further accumulation of keratin leading to further deterioration of cell cleaning (reproduced with modification with permission from [24]).

and Chole [33] investigated the migration rate and patterns for keratin on the tympanic membrane of the gerbil and guinea pig in comparison to human data and indicated that the gerbil was an appropriate model for cholesteatoma because gerbils quite closely resemble humans in rate and pattern of epithelial migration.

In this paper, we summarize the described models for experimentally induced cholesteatoma and introduce our animal models. 


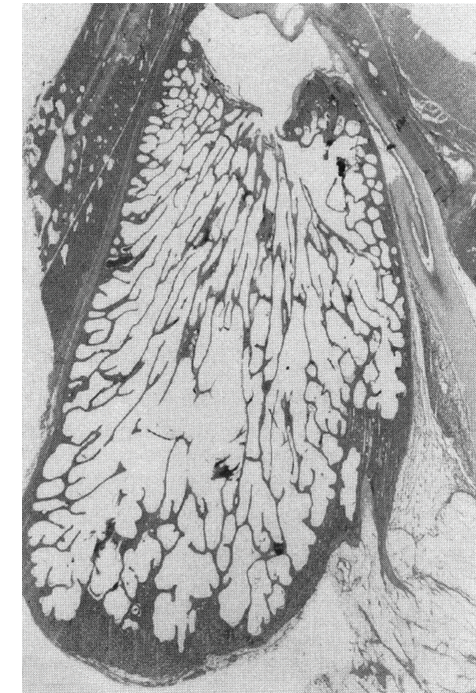

FIGURE 2: Macroscopically photos of the largest section of the mastoid process in pig (reproduced with modification with permission from I Friedmann [29]).

\section{Ligation of the External Ear Canal Model in the Mongolian Gerbil}

Although the spontaneous gerbilline cholesteatoma [30] is useful for studying the pathogenesis of cholesteatoma, the experimental ligation technique of the external ear canal in gerbils is more valuable in predicting the stage of the cholesteatoma [26, 34]. Mongolian gerbils between 2 and 6 months of age were used in this experiment. Under anesthesia, the ear canal was ligated through a curvilinear incision behind the pinna. These experimentally induced cholesteatomas developed in $100 \%$ of the ligated ears. Some 6-9 months after ligation of the external auditory canal, these cholesteatomas are in contact with the bone of the middle ear. These induced cholesteatomas were seen to erode bone and displace soft tissue structures, as is typical of human aural cholesteatomas (Figure 4, [26]). From a surgical point of view, this model is easy to handle, with a high percentage of success. This animal model has been proved to be useful and informative regarding retraction pocket formation and cholesteatoma development.

Several studies were done using this model. In 1999, Kim and Chung [35] examined the distribution of cytokeratin and the binding patterns of lectin in experimental cholesteatoma specimens. They concluded that the origin of aural cholesteatoma may be the external auditory canal epidermal cells, and the characteristics of these cells do not change once the cholesteatoma develops. They also suggested that cholesteatoma have a different biological nature from that of normal epithelial cells, especially basal cells. Larsson et al. [36] performed the acoustic admittance measurements and morphological analysis in experimental cholesteatoma and tympanic membrane. They indicated that the thickness of the fibrous layer was almost doubled, mostly because of an increased amount of collagen fibers, and the acoustic stiffness was significantly increased in all cholesteatoma ears.
Park et al. investigated the immunohistochemical study of cell proliferation using BrdU labeling [37] and the expression of PLG-gamma1, ligand-mediated signal transduction for cell proliferation [38] on the tympanic membrane, external auditory canal, and induced cholesteatoma in gerbils. According to the results, the induced aural cholesteatoma showed a more active proliferation center of the epithelial cell and more intense immunolabeling of PLG-gamma1 protein than the eardrum and external ear canal of the normal gerbil. Tinling and Chole [39] also indicated the hyperproliferation of kertinocytes to be a causative factor in the development and progression of spontaneous and experimental cholesteatomas in this gerbilline model.

\section{Eustachian Tube Blocking Model in the Mongolian Gerbil}

The cornerstone of the retraction pocket theory is that Eustachian tube obstruction leads to negative middle ear pressure, middle ear effusion, and retraction of the pars flaccida into the epitympanum, and subsequent cholesteatoma. To evaluate the evidence of this theory, the Eustachian tube blocking model was developed by Wolfman and Chole in 1986 [27]. Bilateral Eustachian tube obstruction by electrocauterization of the nasopharyngeal portion was performed in gerbils.

Mongolian gerbils between 6 to 10 weeks of age were used in this experiment. After each animal was anesthetized, they attempted to gain exposure of the tubal orifice by slitting the soft palate in the midline (Figure 5(a), [27]). A cautery tip was then inserted through the soft palate in the midline and rotated so as to contact the right and left nasopharyngeal walls, respectively (Figure 5(b), [27]). The results of their study were as follows (Figure 6, [27]). At two weeks, all animals had bilateral serous effusions and retraction pockets. At four weeks, four of eight ears had middle ear fluid, retractions, and cholesteatomas. After eight weeks, five of eight ears had middle ear effusions, and four of these had cholesteatomas; one ear had total atelectasis with a cholesteatoma filling the bulla. By 16 weeks, six of eight ears had developed cholesteatomas.

This study provides experimental evidence that aural cholesteatomas may arise by retraction of the tympanic membrane. In 2001, they suggested that the expression pattern of cytokeratin in retraction pocket cholesteatoma is different from that in normal skin and that the transmigration and hyperproliferation process of squamous epithelium occurs in areas adjacent to the aural cholesteatoma [40]. Using this model, Wilmoth et al. [41] suggested that the elevation of tumor necrosis factor-alpha and matrix metalloproteinases associated with progressive tympanic membrane atelectasis indicated a possible role for these inflammatory mediators in the pathogenesis of cholesteatoma.

\section{Chemical Injection into the Middle Ear in the Chinchilla, Guinea Pig, and Rat}

It was known that chemical injection into the middle ear led to the occurrence of inflammatory change and cholesteatoma 


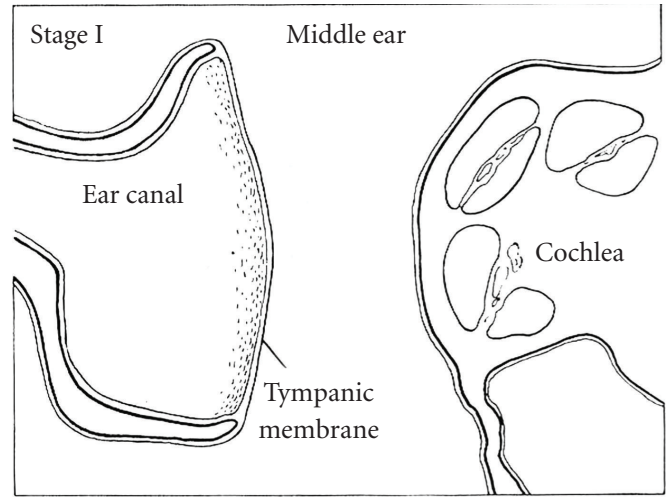

(a)

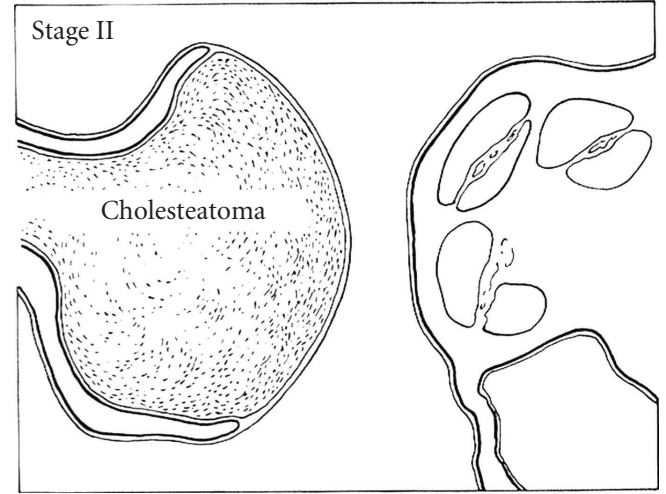

(b)

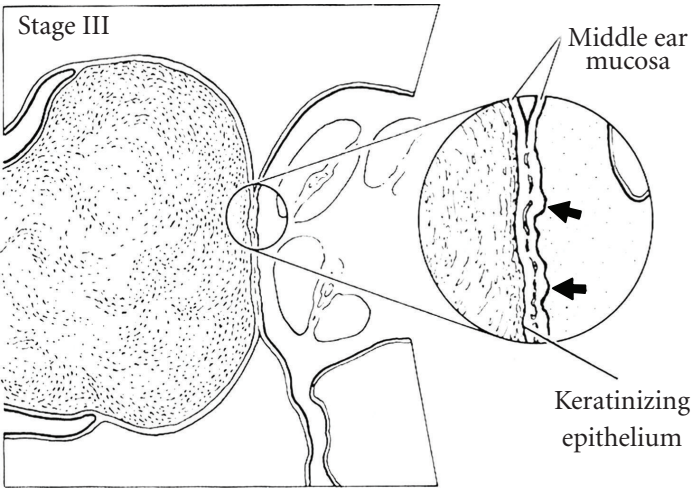

(c)

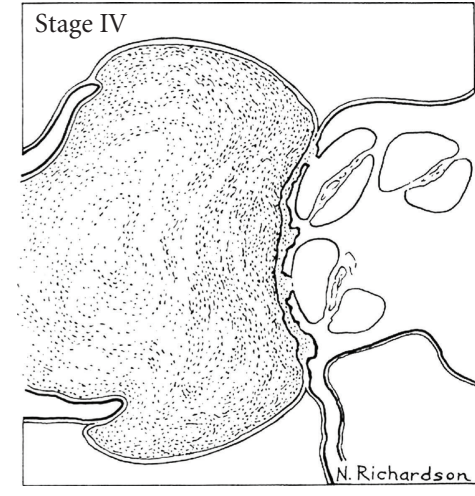

(d)

FIGURE 3: Stages of gerbilline cholesteatoma (reproduced with modification with permission from Henry et al. [30]). Stage I is accumulation of keratin debris on outside surface of tympanic membrane; stage II is medial displacement of tympanic membrane into middle ear without contact with middle wall of bulla; stage III is contact of cholesteatoma with prominence of cochlea (arrows point to early bone erosion); stage is IV cholesteatoma filling bulla; stage V (not shown) intracranial extension of cholesteatoma (reproduced with modification with permission from [30]).

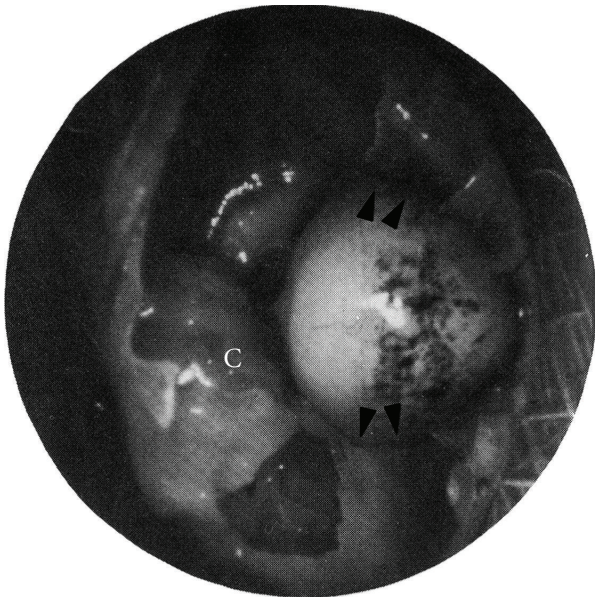

FIgURE 4: Photograph of gerbilline middle ear 2 months after ligation of external auditory canal (reproduced with modification with permission from McGinn et al. [26]). The cholesteatoma has eroded the bone of the tympanic annulus (arrows) and is bulging toward the cochlea $(\mathrm{C})$ (reproduced with modification with permission from [26]). formation. An animal model of cholesteatoma was made by using these chemicals in guinea pigs or rats $[42,43]$.

Placing a mixture of talcum powder and fibrin in the bulla of a guinea pig results in a typical cholesteatoma. It originates from the epidermal basal cells of the tympanic membrane and migrates into the middle ear. This corroborates the epithelial migration theory [42]. Schmid and Hellstrom [43] induced the cholesteatoma formation in rats by using dimethyl-benzanthrancene (DMBA). DMBA is a chemical carcinogen widely used for experimental purposes [44]. After perforating the upper quadrant of the tympanic membrane of a rat, the perforation was exposed to DMBA four times at weekly intervals. They successfully made a cholesteatoma formation in rats. Propylene glycol (PG) has been shown to cause epithelial migration and cholesteatomatous chronic otitis media in North-American chinchillas using optic drops (Cortisporin) containing PG (10\%) [45]. Increasing the dose of PG in topical preparations injected transtympanically yields cholesteatomas $[46,47]$ in a progressively higher percentage of rats, reaching $100 \%$ at a concentration of $90 \%$. 


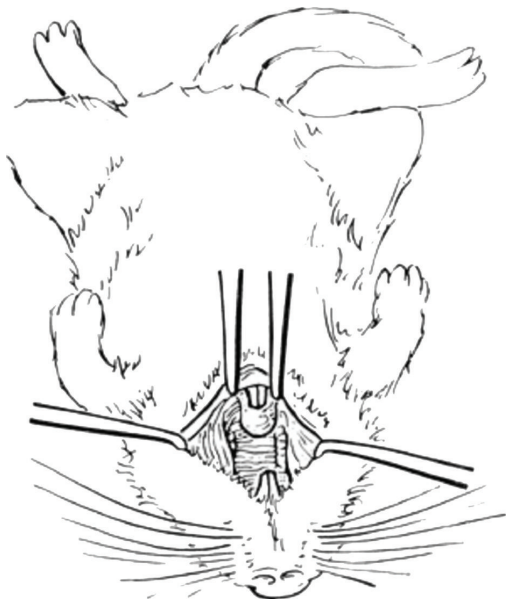

(a)

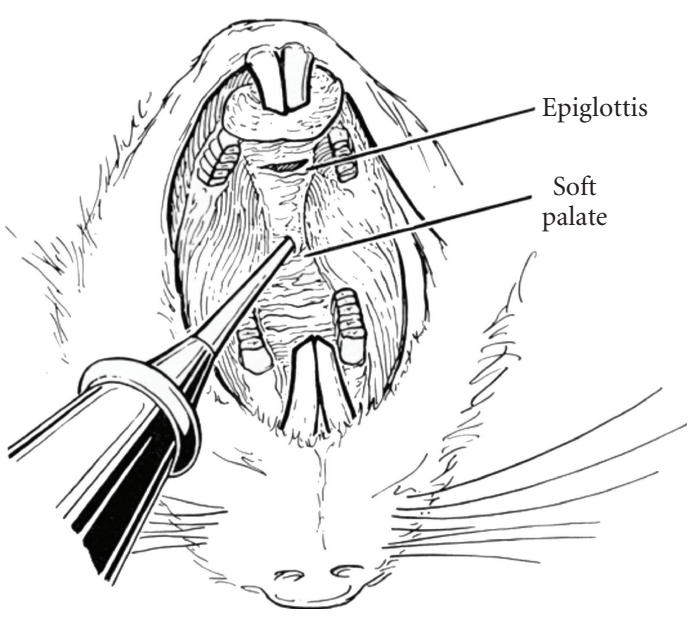

(b)

FIgURE 5: Eustachian tube cauterization (reproduced with modification with permission from Wolfman and Chole [27]). (a) Positioning of supine animal (reproduced with modification with permission from Wolfman and Chole [27]). (b) Cautery tip introduced through midline of soft palate and directed laterally. Eustachian tube orifice is approximately $5 \mathrm{~mm}$ posterior to junction of hard and soft palates (reproduced with modification with permission from Wolfman and Chole [27]).

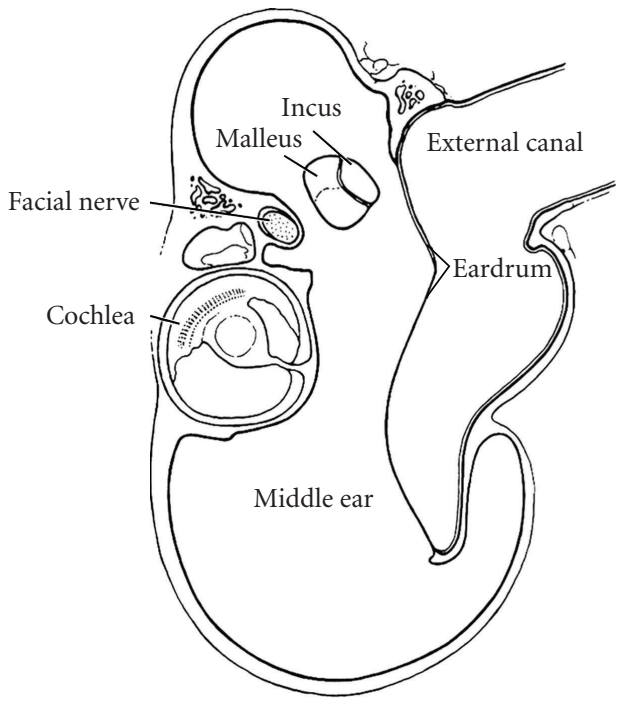

(a)

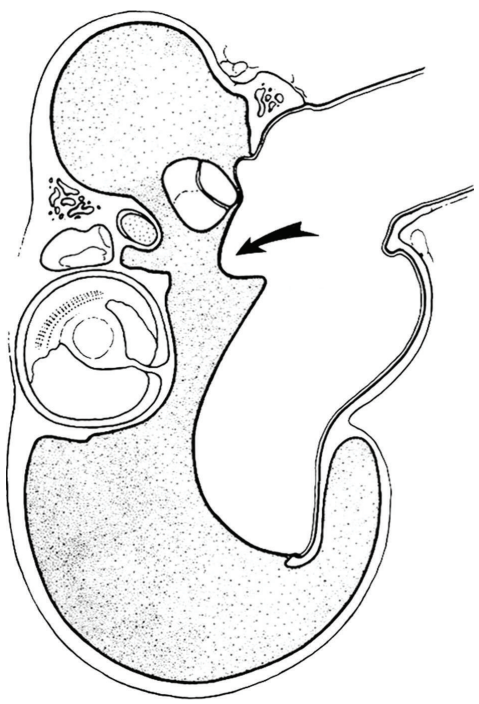

(b)

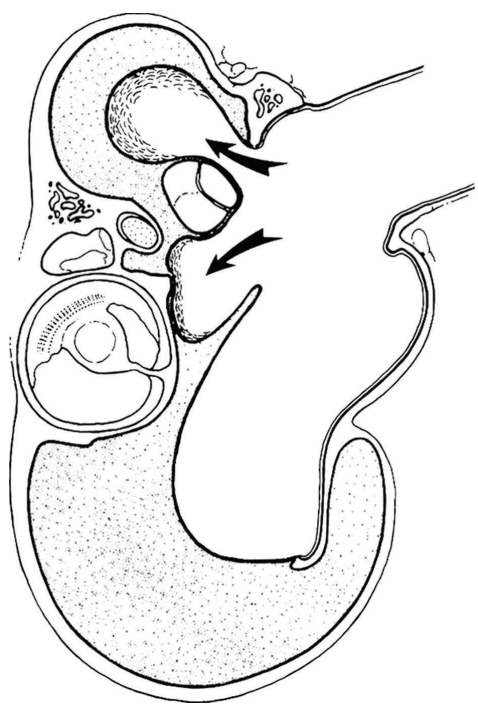

(c)

FIGURE 6: Diagram of coronal section through bulla of gerbil written by Wolfman and Chole [27]. (a) Normal gerbil (reproduced with modification with permission from Wolfman and Chole [27]). (b) After Eustachian tube cauterization, effusion develops (shaded area) and tympanic membrane retracts (reproduced with modification with permission from Wolfman and Chole [27]). (c) With time, pars flaccida retracts into deep pockets, where keratin accumulates (arrows) (reproduced with modification with permission from Wolfman and Chole [27]).

Several studies were done in another to establish new therapies as alternative to surgery for middle ear cholesteatomas using these models. After producing a cholesteatoma in chinchillas by using PG (60\%), 5-fluorouracil was used to inhibit growth of the cholesteatoma with satisfactory results [48]. Hyaluronic acid was applied to the external ear of chinchillas in an attempt to inhibit PG-induced cholesteatoma development with poor results [49]. Similarly, poor results were seen when using cyclophosphamide systemically in chinchillas [50]. The local use of the tran- sretinoic acid is effective in inhibiting the induced formation of cholesteatomas in guinea pigs [51].

\section{Biological Material Injection into the Middle Ear in the Mongolian Gerbil, Guinea Pig and Rat}

Cholesteatoma is a squamous cell cyst, characterized by keratinizing epidermal tissue that can migrate and erode to 
adjacent structures frequently found in temporal bones. An animal model of cholesteatoma was made by using dermal tissues in the middle ears of animals [52-54]. Mongolian gerbils, guinea pigs and rats were used in this experiment. After each animal was anesthetized, a retroauricular skin incision was made following abrasion of the graft in the opposite ear. The dorsal bulla was opened, and the whole of the mucosal lining was carefully removed. The graft, taken from the external ear canal or from other parts of the body, was then placed so that the subepithelial plane faced the exposed bone. The opening of the bulla was covered with a piece of temporalis muscle and the wound sutured.

According to the results, full-thickness skin grafts transplanted into the middle ear with superimposed infections induced expansive growth and cholesteatoma development [52-54]. The success rate of cholesteatoma formation was $89.3 \%$. But, these cholesteatoma did not cause bone erosion.

\section{The Autologous Dermal Implantation Mouse Model}

To circumvent limitations of the previous models and their unpredictable degree of bone resorption, Chole et al. [55] developed a new model of bone resorption in mouse calvarias using keratin particles.

Under anesthesia, murine keratin collected from the nails and fur of mice was implanted onto the dissected calvarium of mature mice. The caused an activation of osteoclasts in the adjacent bone in a manner similar to that seen in human cholesteatoma and in particle-induced osteolysis (Figure 7) [55]. This model was useful in investigating the pathological bone remodeling related to cholesteatoma in a genetically well-defined animal. Many of the genes and their products that control the inflammatory process are well characterized in this mouse model.

Based on their findings, Sudhoff et al. [56, 57] also used this dermal implanting model to investigate bone resorption observed in middle ear cholesteatoma. They concluded that the dermal implant tissue remained viable and produced a robust, localized inflammatory osteolytic response on the adjacent calvarial surface and that osteoclasts were predominantly found on the surface of the calvarium with the greatest osteoclast density under the increased expression of osteoprotegerin (OPG), OPG ligand, and macrophagecolony stimulating factor.

\section{A Local Hybrid Ear Model of Experimentally Induced Cholesteatoma in the Mongolian Gerbil}

To investigate the origin of the epithelial cells of cholesteatoma, whether from the epithelial cells of the external auditory canal or the tympanic membrane, in a previous study, we described a new animal model named "local hybrid ear model" and used in situ PCR, which can detect a few copies of genes within a cell in the section by amplifying the target gene $[58,59]$.

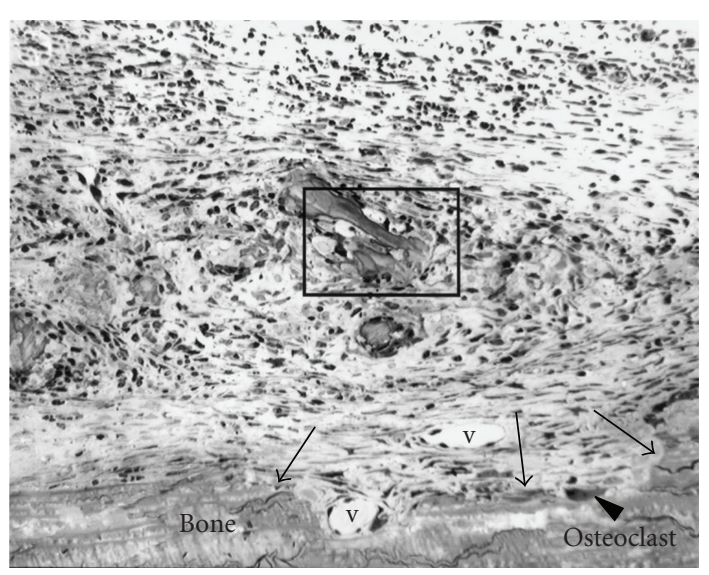

(a)

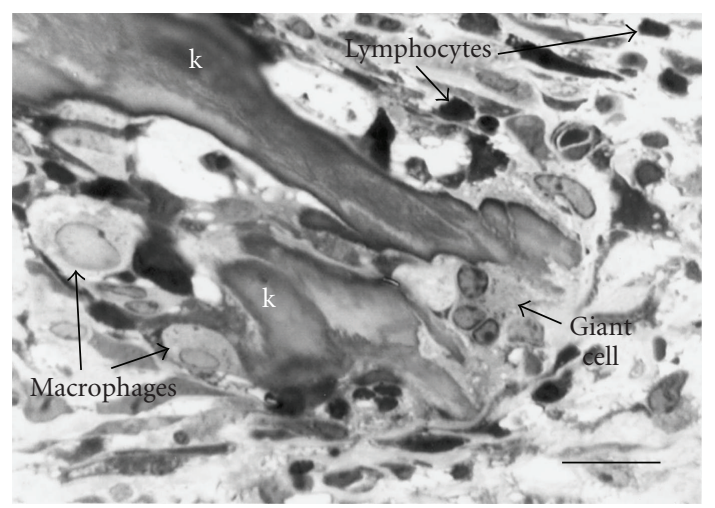

(b)

FIGURE 7: Inflammatory response typical of the site of keratin implant at 1 week survival (reproduced with modification with permission from Chole et al. [55]). The irregular surface of the bone (arrows) is suggestive of erosion though few surface osteoclasts are seen at this time (reproduced with modification with permission from Chole et al. [55]). New vessels (v) are evident, and, at higher power (inset, (b)), the remains of keratin debris $(\mathrm{k})$ can be seen surrounded by macrophages, lymphocytes, and giant cells (reproduced with modification with permission from Chole et al. [55]).

Cholesteatomas were induced in gerbils with transplanted tympanic membranes using the ear auditory canal ligation method. After the pars flaccida of the tympanic membranes were completely removed from male gerbils, corresponding portions of tympanic membranes obtained from the ear of female gerbils were transplanted to the area of defect in the tympanic membranes. We then ligated the external auditory canal of the "hybrid-model" group. As a control group, the ear auditory canal of normal male and female gerbils was ligated without previous myringoplasty. Cholesteatomas were produced in all ears of each group. The origin of cholesteatoma cells was analyzed by the identification of male (XY) or female (XX) cells in the tissue section. Thus, in situ PCR was performed to detect the mouse X-chromosome-linked phosphoglycerate kinase1 (pgk-1) gene on the paraffin sections [60-62]. As a result, 


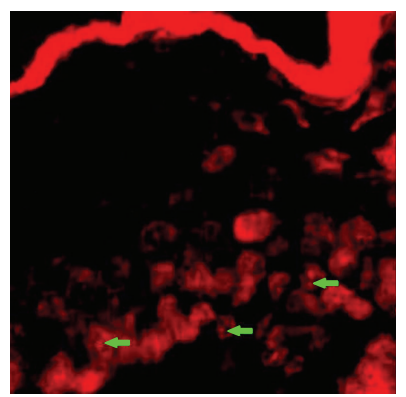

(a)

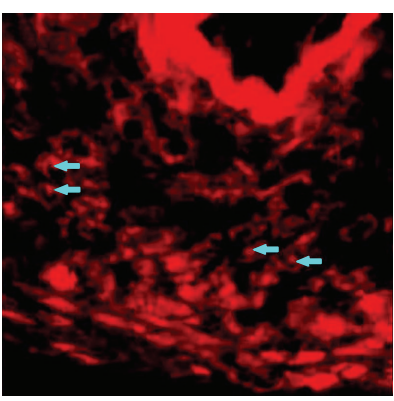

(b)

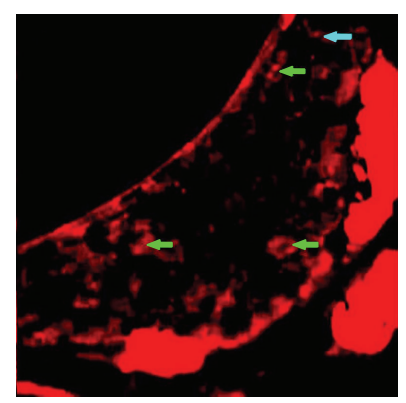

(c)

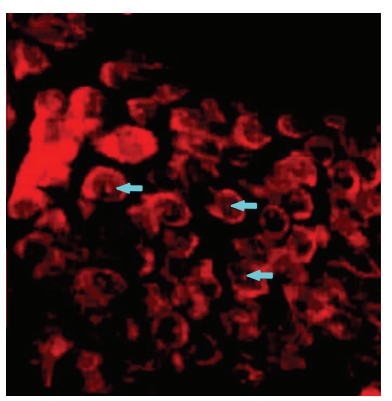

(d)

FIGURE 8: In situ PCR in local hybrid ear model and control (reproduced with modification with permission from Yamamoto-Fukuda et al. [58]). (a) One pgk-1 spot in the nuclei of epithelial cells was detected in male. (b) One or two pgk-1 spot(s) were detected in female cholesteatoma, respectively (reproduced with modification with permission from Yamamoto-Fukuda et al. [58]). (c) One or two pgk-1 $\operatorname{spot}(\mathrm{s})$ were detected in the epithelial nuclei of cholesteatoma (reproduced with modification with permission from Yamamoto-Fukuda et al. [58]). (d) On the other hand, one pgk-1 spot was detected in the cells of EAC (reproduced with modification with permission from Yamamoto-Fukuda et al. [58]). Magnification, $\times 350$. Green arrows: two spots. Blue arrows: one spot.

one pgk-1 spot in the epithelial nuclei was detected in male cholesteatoma (Figure $8(\mathrm{a})$ ), and one or two pgk-1 spots were detected in female cholesteatoma (Figure $8(\mathrm{~b}))$. On the other hand, in the hybrid-model group, we detected not only one but two pgk-1 spots in the epithelial nuclei of cholesteatoma (Figure 8(c)) and one pgk-1 spot was detected in the cells of the ear auditory canal (Figure 8(d)). The percentage of the number of cells having one pgk-1 spot or two pgk-1 spots of cholesteatoma in the hybrid model was almost the same as that of female cholesteatoma. These results indicated that all cholesteatoma cells in the hybrid model have XX chromosomes that were female tissue origin. The results strongly demonstrated evidence that the origin of epithelial cells in cholesteatoma is the tympanic membrane, not residential middle ear epithelial cells or the skin of the external ear canal, in this hybrid model of cholesteatoma.

\section{Conclusion and Future Prospects for Animal Models}

Animal model studies on the pathogenesis of cholesteatoma have led to an improved comprehension of this disease. Mongolian gerbils have a remarkable propensity for the development of aural cholesteatoma; canal cholesteatomas develop spontaneously in aged animals. Cholesteatomas were produced by five different methods of induction: (1) ligation of the external ear canal, (2) Eustachian tube blocking, (3) chemical or free skin graft injection into the middle ear, (4) the autologous dermal implantation model, and (5) a local hybrid-ear model of experimentally induced cholesteatoma. As shown in Table 1, we summarized the advantages and disadvantages of each model. Depending upon the purpose of studying the pathogenesis of cholesteatoma, we should select an appropriable model among them.

In the previous study, gerbilline cholesteatomas induced by these three methods (method 1 method 3) were compared by Kim and Chole [63]. These animal models proved to be useful and informative regarding retraction pocket formation and cholesteatoma development. As a result, the appearance rates of cholesteatoma in each group were almost the same, but the patterns of epithelial hyperplasia, keratin accumulation, thickening of the tympanic membrane, and adhesions of the tympanic membrane were different among the three groups. Also, in 2002, Kim et al. [64] detected prominent changes in the expression of markers for migration and hyperproliferation in gerbilline cholesteatomas produced by three methods compared with that in the tympanic membrane, and their results supported the epidermal migration theory. As in their previous study, the expression patterns of epithelial markers in gerbilline cholesteatomas produced by the three methods were not similar. They concluded that each of the three methods of inducing cholesteatoma may be helpful in investigating different clinical aspects of this disease. On the other hand, in 2007, Choufani et al. [65] performed the quantitative comparison of eight biological markers involved in inflammation, cell differentiation, and cell adhesion/apoptosis between sections of the ligated external ear canal animal model (Method 1) and clinical specimen. Their results indicated that the majority of staining parameters was statistically significantly different between sections of the animal model and clinical specimen from the panel of the above markers. They concluded that from a surgical point of view, this model was easy to handle, with a high percentage of success, thereby allowing one to quickly obtain an external auditory duct cholesteatoma. However, these data did not support the concept of complete validity of the popular animal model.

The problem with the previous method 1 to method 3 animal models was that the morphological aspects were almost the same as human cholesteatoma, but the immunohistochemical results were not strictly the same. In the recent study, we modified the auditory canal ligation model to investigate the origin of the cholesteatoma cells [58]. We analyzed spontaneously occurring cholesteatomas associated with a new transplantation model in gerbils, and using pgk-1 as a tracer provided evidence that transplanted tympanic membranes were the origin of the epithelial cells associated with the development of auditory canal-ligated 
TABLE 1: Comparison of advantages among experimental cholesteatoma models.

\begin{tabular}{|c|c|c|c|c|c|}
\hline & Purpose of analysis & Specie & Surgery & $\begin{array}{c}\text { Percentage of } \\
\text { cholesteatoma } \\
\text { occurrence }\end{array}$ & Advantage \\
\hline $\begin{array}{l}\text { (1) Ligation of } \\
\text { the external ear } \\
\text { canal }\end{array}$ & $\begin{array}{l}\text { Epithelial migration } \\
\text { theory }\end{array}$ & $\begin{array}{l}\text { Mongolian } \\
\text { gerbil }\end{array}$ & Easy & High & Easy to handle \\
\hline $\begin{array}{l}\text { (2) Eustachian } \\
\text { tube blocking }\end{array}$ & $\begin{array}{l}\text { Retraction pocket } \\
\text { theory }\end{array}$ & $\begin{array}{l}\text { Mongolian } \\
\text { gerbil }\end{array}$ & $\begin{array}{l}\text { Slightly } \\
\text { difficult }\end{array}$ & Moderate & $\begin{array}{l}\text { Useful for analysis of } \\
\text { inflammatory mediators }\end{array}$ \\
\hline $\begin{array}{l}\text { (3) Chemical } \\
\text { injection into the } \\
\text { middle ear }\end{array}$ & $\begin{array}{l}\text { Cholesteatomatous } \\
\text { chronic otitis media }\end{array}$ & $\begin{array}{c}\text { Chinchilla } \\
\text { Guinea-pig Rat }\end{array}$ & Easy & High & $\begin{array}{l}\text { Useful for administering } \\
\text { study }\end{array}$ \\
\hline $\begin{array}{l}\text { (4) Biological } \\
\text { material injection } \\
\text { into the middle } \\
\text { ear }\end{array}$ & Immigration theory & $\begin{array}{c}\text { Mongolian } \\
\text { gerbil } \\
\text { Guinea-pig Rat }\end{array}$ & $\begin{array}{l}\text { Slightly } \\
\text { difficult }\end{array}$ & Moderate & $\begin{array}{l}\text { Useful for analysis of } \\
\text { immigratrion theory }\end{array}$ \\
\hline $\begin{array}{l}\text { (5) Autologous } \\
\text { dermal } \\
\text { implantation }\end{array}$ & Bone destruction & Mouse & $\begin{array}{l}\text { Slightly } \\
\text { difficult }\end{array}$ & High & $\begin{array}{l}\text { Useful for investigate } \\
\text { pathological mechanism } \\
\text { of bone destruction }\end{array}$ \\
\hline $\begin{array}{l}\text { (6) Local hybrid } \\
\text { ear model }\end{array}$ & $\begin{array}{l}\text { Origin of the } \\
\text { epithelial cells of } \\
\text { cholesteatoma }\end{array}$ & $\begin{array}{l}\text { Mongolian } \\
\text { gerbil }\end{array}$ & Difficult & High & $\begin{array}{l}\text { Can demonstrate the } \\
\text { origin of the cells of } \\
\text { cholesteatoma correctly }\end{array}$ \\
\hline
\end{tabular}

cholesteatomas in gerbils. The results strongly demonstrated that the origin of epithelial cells in cholesteatoma is the tympanic membrane, but not residential middle ear epithelial cells or the skin of the external ear canal in this hybrid model of cholesteatoma. Accordingly, other studies revealed different protein and cytokeratin profiles between cholesteatoma keratinocytes and epithelial cells of the middle ear $[66,67]$.

Currently, the retraction and proliferation theory has many supporters following clinical observation. Habitual sniffing has clinically been observed to increase the risk of developing retraction pockets and cholesteatoma [68, 69]. Recently, the habitual sniffing-simulating model in gerbils was made by Von Unge and Dircks [70]. The retraction of the tympanic membrane was found, but cholesteatoma formation did not appear. The retraction and proliferation theory is a pathogenesis that combines the retraction caused by otitis media or habitual sniffing and the proliferation of the epithelial cells in the retraction pocket altered by inflammatory stimuli of the subepithelial connective tissue. Therefore, some improvement will be needed to investigate the retraction and proliferation theory using this habitual sniffing model.

Based on the results of inflammatory changes in clinical cholesteatoma specimens, we would like to develop a new animal model in the future. In our previous study, we indicated that keratinocyte growth factor (KGF)/fibroblast growth factor-7 plays an important role in cholesteatoma formation [71]. KGF is a mesenchymal cell-derived paracrine growth factor that specifically stimulates epithelial cell growth and is supposed to be secreted from fibroblasts mainly in stroma binding to KGF receptor, which has only been detected on the surface of epithelial cells [72, 73]. On the other hand, direct in vivo plasmid DNA transfer to the skin via injection has been reported previously [74, 75], and transfer of DNA using electroporation [76] has been demonstrated as a useful procedure for the short-term delivery of gene therapy. We will use KGF-CMV-14 vector [77] and cause overexpression of KGF by electroporatively transfected KGF cDNA in the cells of epithelial tissues in vivo. A single injection of KGF cDNA-expressive vector coupled with electroporation will enhance inflammatory reaction and increase keratinization of epithelium in the auditory canal. This model can possibly be used to investigate the effects of various cytokines and growth factors in cholesteatoma formation in vivo.

The goal of the experiments using animal models is to analyze the pathogenesis of cholesteatoma. Of course, we know that biological differences between animal models and human cholesteatoma would make it difficult to understand the pathogenesis of human cholesteatoma. More suitable models for middle ear cholesteatoma will be needed for future study.

\section{References}

[1] L. A. Harker, "Cholesteatoma an evidence study," in Proceedings of the Cholesteatoma 1st International Conference, B. F. McCabe, J. Sadé, and M. Abramson, Eds., pp. 308-309, Aesculapius, Birmingham, UK, 1977.

[2] M. Tos, "Incidence, etiology and pathogenesis of cholesteatoma in children," Advances in Otorhinolaryngology, vol. 40, pp. 110-117, 1988.

[3] D. Bagger-Sjoback and P. D. Phelps, "Cholesteatoma with extension to the cochlea," American Journal of Otology, vol. 6, no. 4, pp. 338-343, 1985.

[4] R. A. Chole, "Cholesteatoma: conference summary," in Proceedings of the 4th International Conference on Cholesteatoma 
and Mastoid Surgery, Y. Nakano, Ed., pp. 835-840, Kugler, Amsterdam, The Netherlands, 1992.

[5] D. R. Edelstein and S. C. Parisier, "Surgical techniques and recidivism in cholesteatoma," Otolaryngologic Clinics of North America, vol. 22, no. 5, pp. 1029-1040, 1989.

[6] H. Wendt, "Desquamative entundung des mittelohrs ("Cholesteatom des Felsenbeins”)," Arch Heilkunde, vol. 14, p. 428, 1873.

[7] J. Sadé, A. Babiacki, and G. Pinkus, "The metaplastic and congenital origin of cholesteatoma," Acta Oto-Laryngologica, vol. 96, no. 1-2, pp. 119-129, 1983.

[8] J. Sadé, "Retraction pockets and attic cholesteatomas," Acta Oto-Rhino-Laryngologica Belgica, vol. 34, no. 1, pp. 62-84, 1980.

[9] F. Bezold, "Perforation of Shrapnell's membrane and occlusion of the tubes: an aetiological study," Archives of Otolaryngology, vol. 19, pp. 232-254, 1890.

[10] J. Habermann, "Zur entstehung des cholesteatoms des mittelohrs," Archiv für Ohrenheilkunde, vol. 27, no. 1, pp. 42-50, 1889.

[11] I. Friedmann, "Pathogenesis of attic cholesteatoma," Journal of the Royal Society of Medicine, vol. 72, no. 2, p. 154, 1979.

[12] A. Tumarkin, "Attic cholesteatosis," The Journal of Laryngology and Otology, vol. 72, pp. 610-619, 1958.

[13] L. Rüedi, "Pathogenesis and surgical treatment of the middle ear cholesteatoma," Acta Oto-Laryngologica, vol. 361, supplement, pp. 1-45, 1979.

[14] P. Manasse, K. Grunberg, and W. Lange, Handbuch des Pathologischen Anatomie des Menschlichen Ohres, J. F. Bergmann, Wiesbaden, Kingdom of Prussia, 1917.

[15] C. D. Bluestone, E. I. Cantekin, Q. C. Beery, and S. E. Stool, "Function of the Eustachian tube related to surgical management of acquired aural cholesteatoma in children," Laryngoscope, vol. 88, no. 7, pp. 1155-1164, 1978.

[16] B. Magnuson, "Tubal closing failure in retraction type cholesteatoma and adhesive middle ear lesions," Acta OtoLaryngologica, vol. 86, no. 5-6, pp. 408-417, 1978.

[17] B. Magnuson, "On the origin of the high negative pressure in the middle ear space," American Journal of Otolaryngology, vol. 2, no. 1, pp. 1-12, 1981.

[18] B. Magnuson, "Tympanoplasty and recurrent disease: sniffinduced high negative pressure in the middle ear space," American Journal of Otolaryngology, vol. 2, no. 4, pp. 277-283, 1981.

[19] R. Hauser and G. Munker, "Sniff-induced negative pressurea cause of development of middle ear disease?" HNO, vol. 37, no. 6, pp. 242-247, 1989.

[20] T. Kobayashi, Y. Yaginuma, Y. Takahashi, and T. Takasaka, "Incidence of sniff-related cholesteatomas," Acta Oto-Laryngologica, vol. 116, no. 1, pp. 74-76, 1996.

[21] M. Von Unge, W. F. Decraemer, J. J. Dirckx, and D. BaggerSjoback, "Shape and displacement patterns of the gerbil tympanic membrane in experimental: otitis media with effusion," Hearing Research, vol. 82, no. 2, pp. 184-196, 1995.

[22] M. Von Unge, W. F. Decraemer, J. J. Dirckx, and D. BaggerSjöbäck, "Tympanic membrane displacement patterns in experimental cholesteatoma," Hearing Research, vol. 128, no. 1-2, pp. 1-15, 1999.

[23] H. Sudhoff and M. Tos, "Pathogenesis of attic cholesteatoma: clinical and immunohistochemical support for combination of retraction theory and proliferation theory," American Journal of Otology, vol. 21, no. 6, pp. 786-792, 2000.
[24] H. Sudhoff and M. Tos, "Pathogenesis of sinus cholesteatoma," European Archives of Oto-Rhino-Laryngology, vol. 264, no. 10, pp. 1137-1143, 2007.

[25] R. A. Chole, K. R. Henry, and M. D. McGinn, "Cholesteatoma: spontaneous occurrence in the Mongolian gerbil Meriones unguiculatis," American Journal of Otology, vol. 2, no. 3, pp. 204-210, 1981.

[26] M. D. McGinn, R. A. Chole, and K. R. Henry, "Cholesteatona. Experimental induction in the Mongolian gerbil, Meriones unguiculatus," Acta Otolaryngologica, vol. 93, pp. 61-67, 1982.

[27] D. E. Wolfman and R. A. Chole, "Experimental retraction pocket cholesteatoma," Annals of Otology, Rhinology and Laryngology, vol. 95, no. 6 I, pp. 639-644, 1986.

[28] M. M. Hueb, M. V. Goycoolea, D. Muchow, A. J. Duvall, M. M. Paparella, and C. Sheridan, "In search of missing links in otology. III. Development of a new animal model for cholesteatoma," Laryngoscope, vol. 103, no. 7, pp. 774-784, 1993.

[29] I. Friedmann, "The comparative pathology of otitis media, experimental and human-II. The histopathology of experimental otitis of the guinea-pig with particular reference to experimental cholesteatoma," Journal of Laryngology and Otology, vol. 69, no. 9, pp. 588-601, 1955.

[30] K. R. Henry, R. A. Chole, and M. D. McGinn, "Age-related increase of spontaneous aural cholesteatoma in the Mongolian gerbil," Archives of Otolaryngology, vol. 109, no. 1, pp. 19-21, 1983.

[31] R. A. Chole and M. Chiu, "Ultrastructure of middle ear mucosa in the mongolian gerbil, Meriones unguiculatus," Acta Oto-Laryngologica, vol. 100, no. 3-4, pp. 273-288, 1985.

[32] D. G. Jackson and D. J. Lim, "Fine morphology of the advancing front of cholesteatoma-experimental and human," Acta Oto-Laryngologica, vol. 86, no. 1-2, pp. 71-88, 1978.

[33] S. P. Tinling and R. A. Chole, "Gerbilline cholesteatoma development-part I: epithelial migration pattern and rate on the gerbil tympanic membrane: comparisons with human and guinea pig," Otolaryngology, vol. 134, no. 5, pp. 788-793, 2006.

[34] M. D. McGinn, R. A. Chole, and K. R. Henry, "Cholesteatoma induction. Consequences of external auditory ligation in gerbils, cats, hamsters, guinea pigs, mice and rats," Acta OtoLaryngologica, vol. 97, no. 3-4, pp. 297-304, 1984.

[35] C. S. Kim and J. W. Chung, "Morphologic and biologic changes of experimentally induced cholesteatoma in mongolian gerbils with anticytokeratin and lectin study," American Journal of Otology, vol. 20, no. 1, pp. 13-18, 1999.

[36] C. Larsson, M. Von Unge, and D. Bagger-Sjöbäck, “Tympanic membrane changes in experimental cholesteatoma in the gerbil," American Journal of Otology, vol. 20, no. 3, pp. 309316, 1999.

[37] K. Park, Y. M. Chun, H. J. Park, and Y. D. Lee, "Immunohistochemical study of cell proliferation using BrdU labelling on tympanic membrane, external auditory canal and induced cholesteatoma in mongolian gerbils," Acta Oto-Laryngologica, vol. 119, no. 8, pp. 874-879, 1999.

[38] K. Park, Y. M. Chun, and D. H. Lee, "Expression of phospholipase C- $\gamma 1$ in experimental cholesteatoma using Mongolian gerbils," Acta Oto-Laryngologica, vol. 121, no. 4, pp. 477-480, 2001.

[39] S. P. Tinling and R. A. Chole, "Gerbilline cholesteatoma development-part III. Increased proliferation index of basal keratinocytes of the tympanic membrane and external ear canal," Otolaryngology, vol. 135, no. 1, pp. 116-123, 2006. 
[40] H. J. Kim, S. P. Tinling, and R. A. Chole, "Expression patterns of cytokeratins in retraction pocket cholesteatomas," Laryngoscope, vol. 111, no. 6, pp. 1032-1036, 2001.

[41] J. G. Wilmoth, G. S. Schultz, and P. J. Antonelli, "Matrix metalloproteinases in a gerbil cholesteatoma model," Otolaryngology, vol. 129, no. 4, pp. 402-407, 2003.

[42] L. Rüedi, "Cholesteatoma formation in the middle ear in animal experiments," Acta Otolaryngologica, vol. 50, pp. 233242, 1959.

[43] S. H. Schmidt and S. Hellstrom, "Experimental cholesteatoma in the rat," Acta Oto-Laryngologica, vol. 114, no. 4, pp. 430434, 1994.

[44] A. J. P. Klein-Szanto, M. Terzaghi, and L. D. Mirkin, "Propagation of normal human epithelial cell populations using an in vivo culture system. Description and applications," American Journal of Pathology, vol. 108, no. 2, pp. 231-239, 1982.

[45] M. Masaki, C. G. Wright, D. H. Lee, and W. L. Meyerhoff, "Effects of otic drops on chinchilla tympanic membrane," Archives of Otolaryngology, vol. 114, no. 9, pp. 1007-1011, 1988.

[46] L. Vassalli, D. M. Harris, R. Gradini, and E. L. Applebaum, "Propylene glycol-induced cholesteatoma in chinchilla middle ears," American Journal of Otolaryngology, vol. 9, no. 4, pp. 180-188, 1988.

[47] C. C. Huang, G. S. Shi, and Z. X. Yi, "Experimental induction of middle ear cholesteatoma in rats," American Journal of Otolaryngology, vol. 9, no. 4, pp. 165-172, 1988.

[48] C. G. Wright, L. L. Bird, and W. L. Meyerhoff, "Effect of 5 -fluorouracil in cholesteatoma development in an animal model," American Journal of Otolaryngology, vol. 12, no. 3, pp. 133-138, 1991.

[49] S. J. White, C. G. Wright, K. S. Robinson, and W. L. Meyerhoff, "Effect of topical hyaluronic acid on experimental cholesteatoma," American Journal of Otolaryngology, vol. 16, no. 5, pp. 312-318, 1995.

[50] P. H. Pownell, C. G. Wright, K. S. Robinson, and W. L. Meyerhoff, "The effect of cyclophosphamide on development of experimental cholesteatoma," Archives of Otolaryngology Head and Neck Surgery, vol. 120, no. 10, pp. 1114-1116, 1994.

[51] M. L. Antunes, Y. Fukuda, N. D. O. Penido, and R. Ferreira, "Effect of trans-retinoic acid in the inhibition of cholesteatoma in guinea pigsEfeito do ácido trans-retinóico na inibição de colesteatoma em cobaias," Brazilian Journal of Otorhinolaryngology, vol. 74, no. 1, pp. 53-60, 2008.

[52] P. P. C. A. Vennix, W. Kuijpers, T. A. Peters, E. L. G. M. Tonnaer, and F. C. S. Ramaekers, "Growth and differentiation of meatal skin grafts in the middle ear of the rat," Archives of Otolaryngology-Head and Neck Surgery, vol. 120, no. 10, pp. 1102-1111, 1994.

[53] K. Park, Y. M. Chun, S. M. Kim, and D. H. Lee, "Experimental cholesteatoma by transplanting a free skin graft in the bulla of Mongolian gerbil," Korean Journal of Otorhinolaryngology, vol. 39, no. 7, pp. 1138-1143, 1996.

[54] Y. Hinohira, K. Gyo, and N. Yanagihara, "Experimental cholesteatomas arising from autologous free skin grafting in the middle ear cavity," Acta Oto-Laryngologica, vol. 114, no. 5, pp. 533-538, 1994.

[55] R. A. Chole, R. M. Hughes, and B. T. Faddis, "Keratin particle-induced osteolysis: a mouse model of iflammatory bone remodeling related to cholesteatoma," Journal of the Association for Research in Otolaryngology, vol. 2, no. 1, pp. 6571, 2001.
[56] H. Sudhoff, Y. Liebehenz, J. Aschenbrenner, J. Jung, H. Hildmann, and S. Dazert, "A murine model of cholesteatomainduced bone resorption using autologous dermal implantation," Laryngoscope, vol. 113, no. 6, pp. 1022-1026, 2003.

[57] H. Sudhoff, Y. Liebehenz, J. Aschenbrenner et al., "Expression of osteoclast stimulating and differentiating factors in a murine model of localized inflammatory bone resorption," Laryngo-Rhino-Otologie, vol. 83, no. 1, pp. 14-19, 2004.

[58] T. Yamamoto-Fukuda, Y. Hishikawa, Y. Shibata, T. Kobayashi, H. Takahashi, and T. Koji, "Pathogenesis of middle ear cholesteatoma: a new model of experimentally induced cholesteatoma in Mongolian gerbils," American Journal of Pathology, vol. 176, no. 6, pp. 2602-2606, 2010.

[59] PCR 3., PCR In situ Hybridization. A Practical Approach, The Practical Approach Series No. 186, IRL Press at Oxford University Press, 2010.

[60] C. N. Adra, P. H. Boer, and M. W. McBurney, "Cloning and expression of the mouse pgk-1 gene and the nucleotide sequence of its promoter," Gene, vol. 60, no. 1, pp. 65-74, 1987.

[61] J. Singer-Sam, V. Chapman, J. M. LeBon, and A. D. Riggs, "Parental imprinting studied by allele-specific primer extension after PCR: paternal X chromosome-linked genes are transcribed prior to preferential paternal X chromosome inactivation," Proceedings of the National Academy of Sciences of the United States of America, vol. 89, no. 21, pp. 10469-10473, 1992.

[62] Y. Hishikawa, S. An, T. Yamamoto-Fukuda, Y. Shibata, and T. Koji, "Improvement of in situ PCR by optimization of PCR cycle number and proteinase $\mathrm{K}$ concentration: localization of X chromosome-linked phosphoglycerate kinase-1 gene in mouse reproductive organs," Acta Histochemica et Cytochemica, vol. 42, no. 2, pp. 15-21, 2009.

[63] H. J. Kim and R. A. Chole, "Experimental models of aural cholesteatomas in Mongolian gerbils," Annals of Otology, Rhinology and Laryngology, vol. 107, no. 2, pp. 129-134, 1998.

[64] H. J. Kim, S. P. Tinling, and R. A. Chole, "Increased proliferation and migration of epithelium in advancing experimental cholesteatomas," Otology and Neurotology, vol. 23, no. 6, pp. 840-844, 2002.

[65] G. Choufani, N. Roper, C. Delbrouck, S. Hassid, and H. J. Gabius, "Animal model for cholesteatoma induced in the gerbil: will the profiles of differentiation/growth-regulatory markers be similar to the clinical situation?" Laryngoscope, vol. 117, no. 4, pp. 706-711, 2007.

[66] E. Olszewska and H. Sudhoff, "Comparative cytokeratin distribution patterns in cholesteatoma epithelium," Histology and Histopathology, vol. 22, no. 1-3, pp. 37-42, 2007.

[67] Y. Xu, Z. Z. Tao, Q. Q. Hua, X. X. Wang, and B. K. Xiao, "Expression and activation of nuclear factor-kappaB in middle ear cholesteatoma," Zhonghua Er Bi Yan Hou Tou Jing Wai Ke Za Zhi, vol. 41, pp. 455-459, 2006.

[68] B. Magnuson and B. Falk, "Eustachian tube malfunction and middle ear disease in new perspective," Journal of Otolaryngology, vol. 12, no. 3, pp. 187-193, 1983.

[69] B. Falk and B. Magnuson, "Evacuation of the middle ear by sniffing: a cause of high negative pressure and development of middle ear disease," Otolaryngology, vol. 92, no. 3, pp. 312318, 1984.

[70] M. Von Unge and J. J. Dircks, "Functional effects of repeated pressure loads upon the tympanic membrane: mechanical stiffness measurements after simulated habitual sniffing," European Archives of Oto-Rhino-Laryngology, vol. 266, no. 8, pp. 1219-1224, 2009. 
[71] T. Yamamoto-Fukuda, D. Aoki, Y. Hishikawa, T. Kobayashi, H. Takahashi, and T. Koji, "Possible involvement of keratinocyte growth factor and its receptor in enhanced epithelialcell proliferation and acquired recurrence of middle-ear cholesteatoma," Laboratory Investigation, vol. 83, no. 1, pp. 123-136, 2003.

[72] P. W. Finch, J. S. Rubin, T. Miki, D. Ron, and S. A. Aaronson, "Human KGF is FGF-related with properties of a paracrine effector of epithelial cell growth," Science, vol. 245, no. 4919, pp. 752-755, 1989.

[73] T. Koji, M. Chedid, J. S. Rubin et al., "Progesterone-dependent expression of keratinocyte growth factor mRNA in stromal cells of the primate endometrium: keratinocyte growth factor as a progestomedin," Journal of Cell Biology, vol. 125, no. 2, pp. 393-401, 1994.

[74] U. R. Hengge, E. F. Chan, R. A. Foster, P. S. Walker, and J. C. Vogel, "Cytokine gene expression in epidermis with biological effects following injection of naked DNA," Nature Genetics, vol. 10, no. 2, pp. 161-166, 1995.

[75] U. R. Hengge, P. S. Walker, and J. C. Vogel, "Expression of naked DNA in human, pig, and mouse skin," Journal of Clinical Investigation, vol. 97, no. 12, pp. 2911-2916, 1996.

[76] H. Maruyama, K. Ataka, N. Higuchi, F. Sakamoto, F. Gejyo, and J. Miyazaki, "Skin-targeted gene transfer using in vivo electroporation," Gene Therapy, vol. 8, no. 23, pp. 1808-1812, 2001.

[77] K. Matsumoto, T. Nagayasu, Y. Hishikawa et al., "Keratinocyte growth factor accelerates compensatory growth in the remaining lung after trilobectomy in rats," Journal of Thoracic and Cardiovascular Surgery, vol. 137, no. 6, pp. 1499-1507, 2009. 


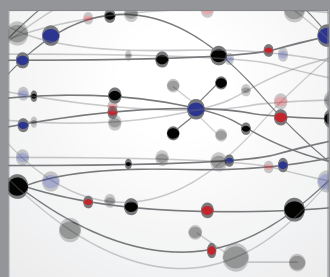

The Scientific World Journal
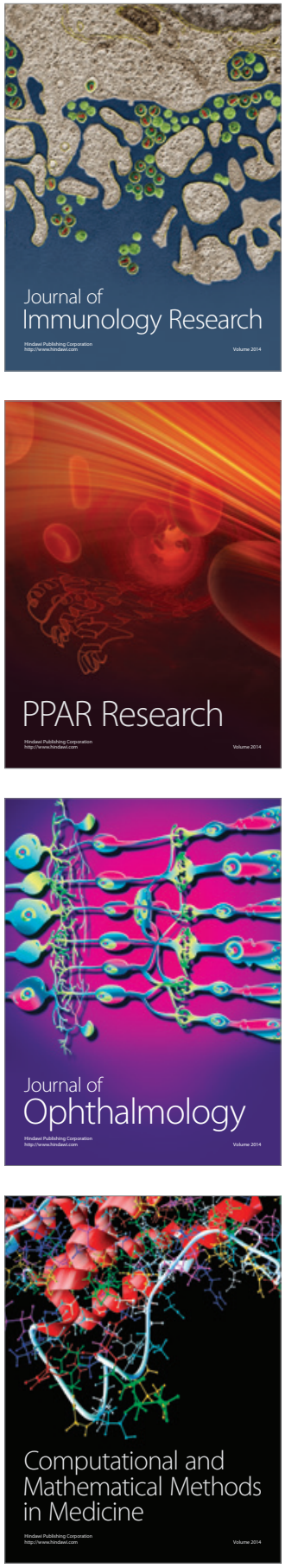

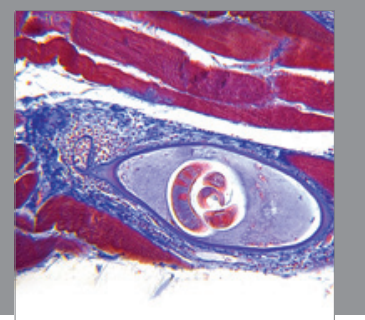

Gastroenterology

Research and Practice
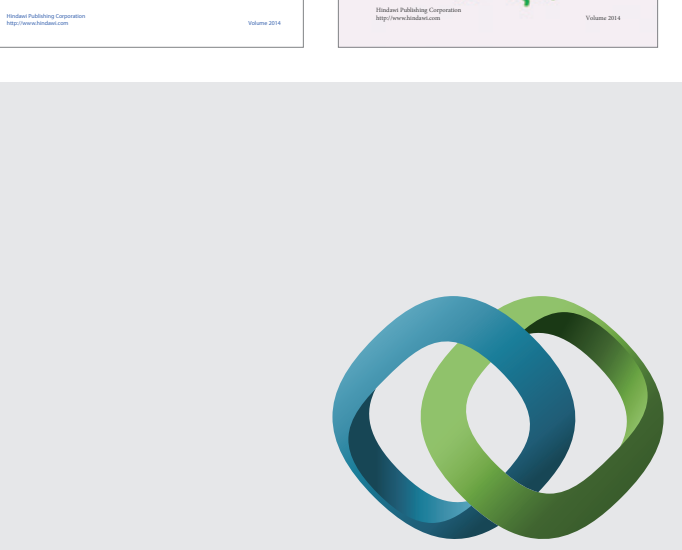

\section{Hindawi}

Submit your manuscripts at

http://www.hindawi.com
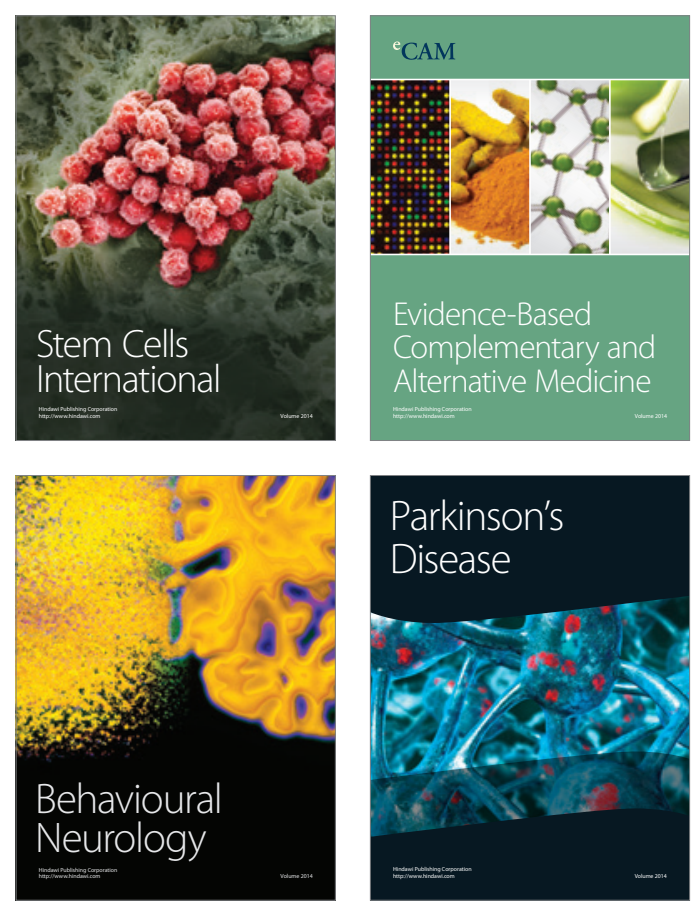

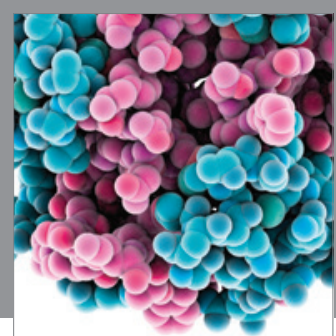

Journal of
Diabetes Research

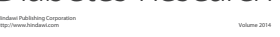

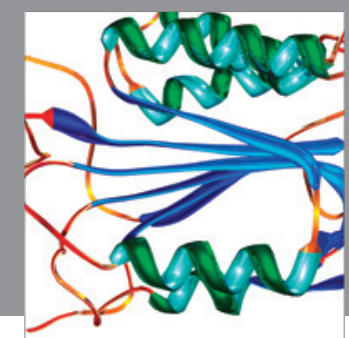

Disease Markers
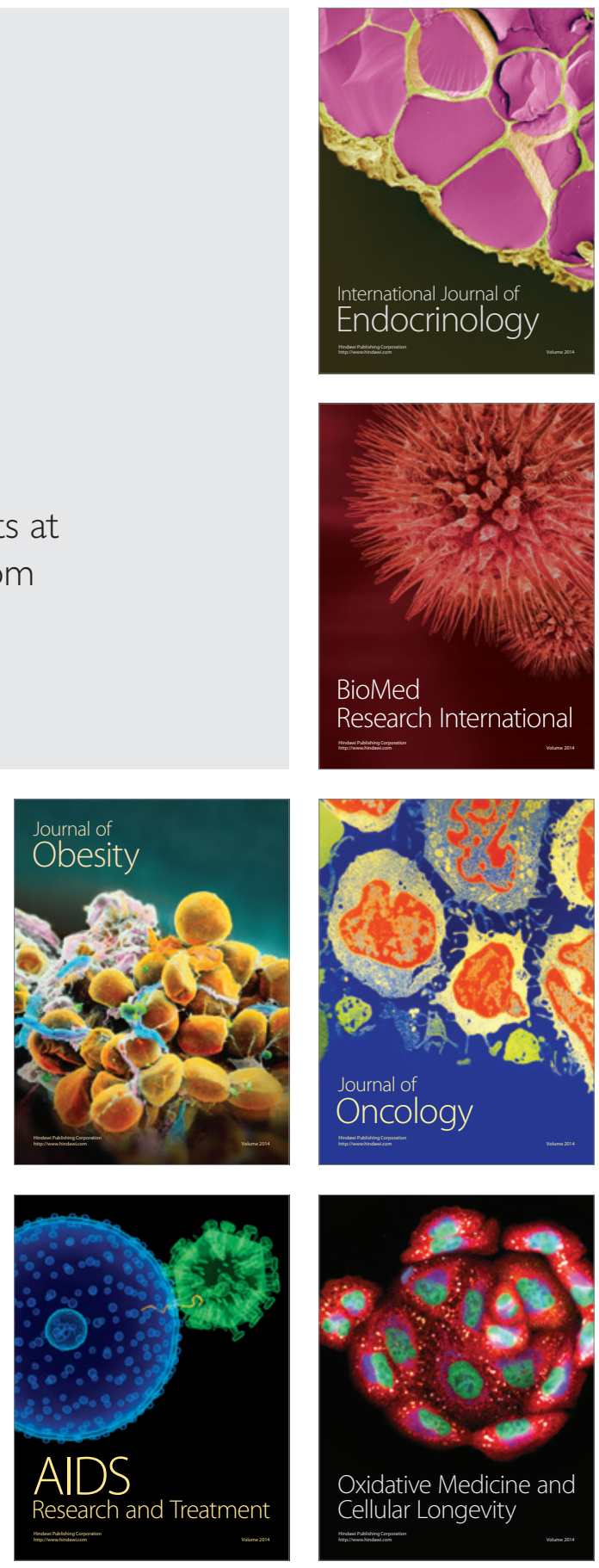